University of South Carolina

Scholar Commons

1996

\title{
Galvanostatic Pulse and Pulse Reverse Plating of Zinc-Nickel Alloys from Sulfate Electrolytes on a Rotating Disc Electrode
}

\author{
Branko Popov \\ University of South Carolina - Columbia, popov@engr.sc.edu \\ M. Ramasubramanian \\ University of South Carolina - Columbia \\ S. N. Popova \\ University of South Carolina - Columbia \\ Ralph E. White \\ University of South Carolina - Columbia, white@cec.sc.edu \\ Ken-Ming Yin \\ University of South Carolina - Columbia \\ Follow this and additional works at: https://scholarcommons.sc.edu/eche_facpub \\ Part of the Other Chemical Engineering Commons
}

\section{Publication Info \\ Journal of the Chemical Society, Faraday Transactions, Volume 92, Issue 20, 1996, pages 4021-4028. This article cannot be redistributed or further made available. \\ This article was first published by the Royal Society of Chemistry and can be found at http://dx.doi.org/ 10.1039/FT9969204021 \\ Popov, B. N., Ramasubramanian, M., Popova, S. N., White, R. E., \& Yin, K-M. (1996). Galvanostatic Pulse and Pulse Reverse Plating of Zinc-Nickel Alloys from Sulfate electrolytes on a Rotating Disc Electrode. Journal of the Chemical Society, Faraday Transactions, 92, $4021-4028$.}

This Article is brought to you by the Chemical Engineering, Department of at Scholar Commons. It has been accepted for inclusion in Faculty Publications by an authorized administrator of Scholar Commons. For more information, please contact digres@mailbox.sc.edu. 


\title{
Galvanostatic pulse and pulse reverse plating of zinc-nickel alloys
} from sulfate electrolytes on a rotating disc electrode

\author{
B. N. Popov, ${ }^{a}$ M. Ramasubramanian, ${ }^{a}$ S. N. Popova, ${ }^{a}$ R. E. White ${ }^{a}$ and K-M. Yin ${ }^{b}$ \\ a Department of Chemical Engineering, University of South Carolina, Columbia, SC 29208, USA \\ ${ }^{b}$ Department of Chemical Engineering, Yuan-Ze Institute of Technology, Neili, Taoyuan, 32026,
}

Taiwan

Galvanostatic pulse and pulse reverse techniques have been used to study the plating of zinc-nickel alloys in the presence of nonyl phenyl polyethylene oxide. The effects of average current density, rotation speed of disc electrode and the presence of nonyl phenyl polyethylene oxide in the electrolyte on deposition of zinc-nickel alloys were evaluated. Zinc-nickel plating bath solution chemistry was studied by determining the equilibrium concentrations at various $\mathrm{pH}$ levels. It was found that the alloy composition was determined by solution equilibria, mass transfer of the electroactive species within the diffusion layer and by the surface coverage of nonyl phenyl polyethylene oxide.

Anomalous codeposition has been recognized in connection with several alloy deposition systems such as $\mathrm{Fe}-\mathrm{Ni}, \mathrm{Co}-\mathrm{Ni}$ and $\mathrm{Zn}-\mathrm{Ni} .{ }^{1-8}$ In zinc-nickel alloy deposition, zinc deposits at a faster rate leading to a higher concentration of zinc in the alloy composition. This is different from what one would expect based on the composition of the plating solution, where the concentration of nickel ions is higher than that of zinc ions. ${ }^{9-20}$ The effects of pulse plating on zinc-nickel alloy structure in unagitated solutions were studied by Nishimura et $a l^{21}$ They found that the pulse period has a major effect on the alloy crystal size. Off time also affected the nickel content and the structure of the zinc-nickel electrodeposits.

In this study, the effect of mass transfer on the composition of deposited zinc-nickel alloys from sulfate baths was investigated using galvanostatic pulse and pulse reverse plating. The effect of nonyl phenyl polyethylene oxide on the deposit structure and composition was also studied. In our previous study on electrodeposition of zinc from sulfate electrodes, ${ }^{22}$ nonyl phenyl polyethylene oxide inhibited the zinc electrocrystallization process and acted as a levelling agent. The solution chemistry of the sulfate bath used was studied as a function of $\mathrm{pH}$ in order to determine the nature and relative concentrations of the various electroactive species present in the system. This knowledge of the reacting species was used to explain the results obtained from the pulse plating and linear sweep voltammetric experiments.

\section{Experimental}

The electrochemical cell employed was a conventional threecompartment design with contact between the working electrode and the reference electrode compartment via a Luggin probe. Measurements were carried out with a rotating copper disc electrode with a geometric area of $0.6 \mathrm{~cm}^{2}$. Platinum gauze was used as a counter electrode, while a saturated calomel electrode served as a reference electrode.

The experiments were conducted using an EG\&G Instruments Model 351 SoftCorr System. Analytical grade $\mathrm{NiSO}_{4}$, $\mathrm{Na}_{2} \mathrm{SO}_{4}, \mathrm{ZnSO}_{4}$, nonyl phenyl polyethylene oxide (NPO) and high-purity water were used. The $\mathrm{pH}$ of the solution was adjusted with addition of $\mathrm{NaOH}$ or $20 \% \mathrm{H}_{2} \mathrm{SO}_{4}$. Atomic absorption spectroscopy and EDS were used to determine the zinc and nickel contents of the deposits. The surface morphologies were studied using SEM (JEOL JSM-35 CF scanning electron microscope in conjunction with a Northern TN-200 $\mathrm{X}$-ray analysis system).
A schematic of the pulse and pulse reverse wave forms used is shown in Fig. 1. Pulse current was applied by the Potentiostat/Galvanostat Model 273 (PAR). The applied pulse current and the associated potential responses were monitored using an oscilloscope (Textronix 2430A digital oscilloscope). The peak cathodic potential (at the end of $t_{\mathrm{on}}$ ) and the peak anodic potential (at the end of $t_{\mathrm{off}}$ ) were recorded as $E_{\mathrm{p}}$ and $E_{\mathrm{r}}$, respectively.

The average current density is $i_{\mathrm{p}} \times$ (duty cycle), where duty cycle is defined as $t_{\mathrm{on}} /\left(t_{\mathrm{on}}+t_{\mathrm{off}}\right)$. The pulse period $\left(t_{\mathrm{on}}\right)$ and relaxation period $\left(t_{\text {off }}\right)$ were set at $100 \mathrm{~ms}$ each. For the pulse reversal mode $(\mathrm{pr}) i_{\mathrm{r}}=-0.2 i_{\mathrm{p}}$ was used under all operating conditions.

\section{Results and discussion}

\section{Solution chemistry of $\mathrm{Zn}-\mathrm{Ni}$ plating bath}

During alloy deposition at high current densities, the $\mathrm{pH}$ near the electrode surface is much higher than at the bulk due to the parasitic hydrogen evolution reaction. ${ }^{8}$ Hence, a study of the equilibrium formation of various hydroxide species in the bath was carried out in order to identify the different components that exist in a solution at different $\mathrm{pH}$ levels. The

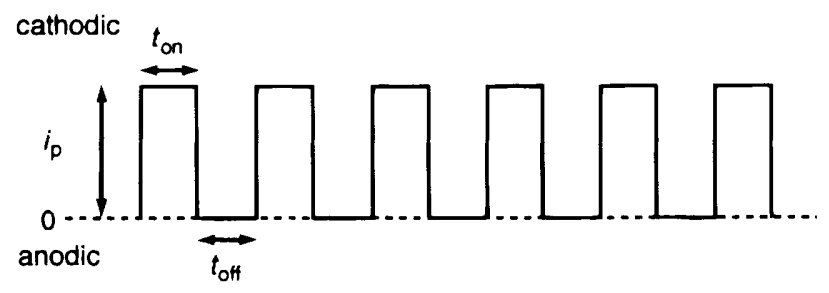

(a) pulse current (pc)

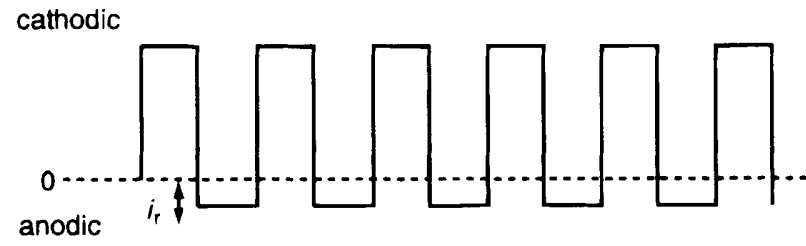

(b) putse with reverse (pr)

Fig. 1 Schematic diagrams of (a) pulse current waves (pc); (b) pulse with reverse (pr) 
concentrations of all electroactive species in the bath were calculated by using equilibrium conditions, various element balances and the electroneutrality condition for a specified $\mathrm{pH}$. Suitable amounts of $\mathrm{NaOH}$ and $\mathrm{H}_{2} \mathrm{SO}_{4}$ were used in the computation to obtain the whole spectrum of $\mathrm{pH}$. The calculations were carried out for a bath containing $0.5 \mathrm{M} \mathrm{NiSO}_{4}$ $+0.2 \mathrm{M} \mathrm{ZnSO}_{4}+0.5 \mathrm{M} \mathrm{Na}_{2} \mathrm{SO}_{4}$. Three different $\mathrm{pH}$ regions have been considered. No precipitation occurs in the first (more acidic) region. Zinc hydroxide precipitates in the second region, and both zinc and nickel hydroxides precipitate in the third. The governing equations for different $\mathrm{pH}$ regions and the computational details are summarized and shown in the Appendix. By using the appropriate set of equations describing the $\mathrm{pH}$ regions, the concentrations of all electroactive species can be estimated for the $\mathrm{pH}$ range from 0 to 14 . The concentrations of the electroactive species assumed to be present in the electrolyte were calculated using MAPLE, ${ }^{23}$ and are presented in Fig. 2 as a function of pH. The results indicate that up to a $\mathrm{pH}$ of 7.1 the ions are predominantly in their respective bivalent states. $\mathrm{Zn}(\mathrm{OH})_{2}$ starts to precipitate at a $\mathrm{pH}$ of 7.1 and $\mathrm{Ni}(\mathrm{OH})_{2}$ at 7.3. The concentration of both metal monohydroxide ions, $\mathrm{Ni}(\mathrm{OH})^{+}$and $\mathrm{Fe}(\mathrm{OH})^{+}$, increases with an increase in $\mathrm{pH}$ and reaches a maximum value just before the precipitation of their respective hydroxides starts to occur. Trivalent zinc ion, $\mathrm{Zn}_{2}(\mathrm{OH})^{3+}$, also shows a similar behaviour. Fig. 2 illustrates the importance of the $\mathrm{pH}$ study of the system considered. It shows that the concentration of any electroactive species depends to a great extent on the system $\mathrm{pH}$. Apart from having an effect on the mass transfer of any diffusion controlled species, electrolyte agitation would also change the nature of the species present at the electrode surface by influencing the $\mathrm{pH}$. Even though the results obtained in Fig. 2 are for bulk equilibrium conditions, they stress the importance of $\mathrm{pH}$ and agitation conditions on the final alloy composition.

\section{Linear sweep voltammetry (LSV)}

LSV was used as an in situ technique to characterize the electrochemically formed thin layers of zinc, nickel and zincnickel alloys. The studies were carried out using fixed and rotating copper disc electrodes. The LSVs of pure metal deposition were compared with those when both metals are present in solution in order to obtain information on any interaction between the alloy deposition process and deposited metals.

Potentiodynamic stripping voltammograms of a zinc film electrodeposited from a solution containing $0.2 \mathrm{M} \mathrm{ZnSO}_{4}$ $+0.5 \mathrm{M} \mathrm{Na}_{2} \mathrm{SO}_{4}$ at pH 2.5 and $v=30 \mathrm{mV} \mathrm{s}^{-1}$ in the absence and presence of convection are shown in Fig. 3. In the absence of convection, the voltammogram obtained shows a cathodic peak at $-1.2 \mathrm{~V}$ vs. SCE, which can be attributed to both

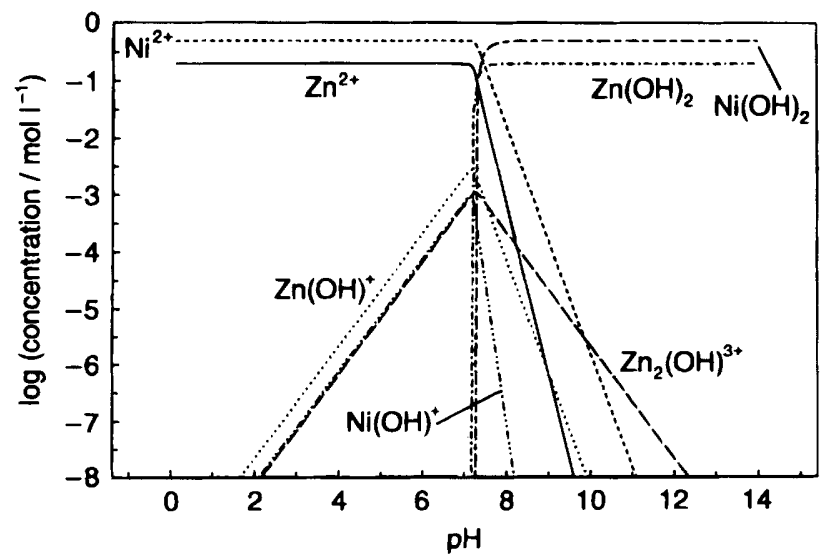

Fig. 2 Solution equilibrium concentrations of a $\mathrm{Zn}-\mathrm{Ni}$ plating bath as a function of $\mathrm{pH}$

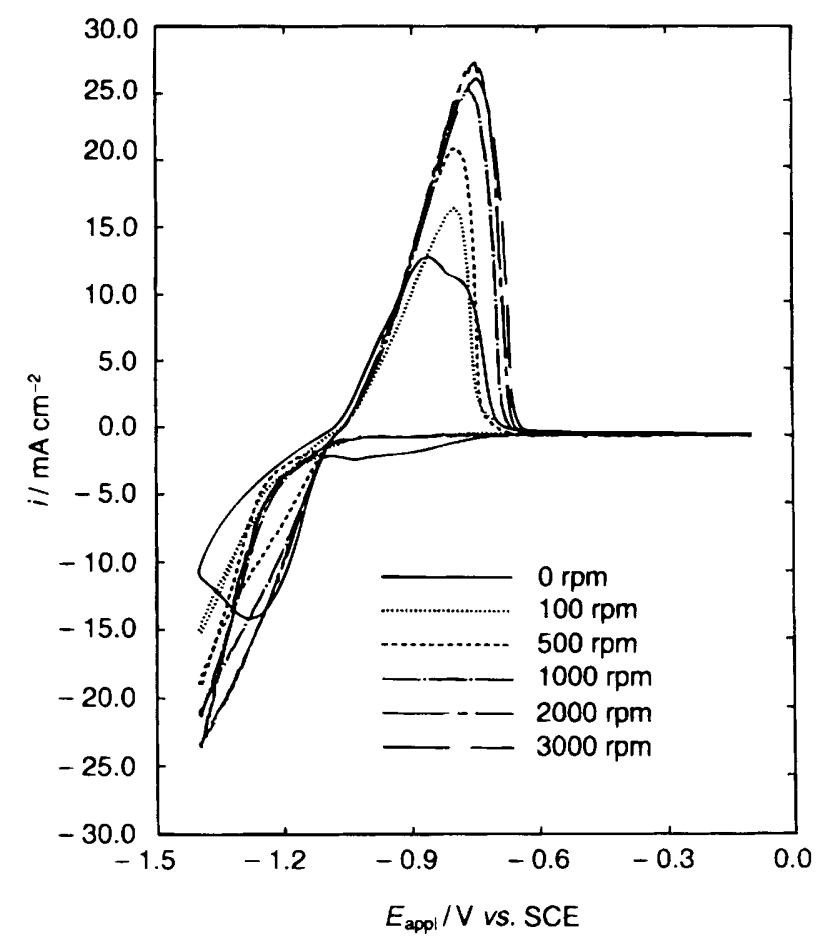

Fig. 3 Potentiodynamic stripping voltammograms of a zinc film electrodeposited from electrolyte containing $0.2 \mathrm{M} \mathrm{ZnSO}_{4}+0.5 \mathrm{M}$ $\mathrm{Na}_{2} \mathrm{SO}_{4}$ at $\mathrm{pH} 2.5$ at different rotation speeds

hydrogen evolution and zinc deposition reactions. At more cathodic overpotentials, the cathodic current obtained is due to the water reduction reaction. In the presence of convection, the peak disappears and is replaced by a monotonically increasing cathodic current. This occurs as a result of a greater availability of $\mathrm{H}^{+}$and zinc ions for reduction. However, under both conditions the cathodic zinc deposition peak cannot be isolated from that of hydrogen evolution. Hence the anodic zinc dissolution peak, which can be isolated, was used to interpret the deposition of zinc. An increase in the anodic peak area is observed in Fig. 3 as the rotation rate of the electrode is increased. Previous studies ${ }^{24}$ indicate that the zinc deposition from sulfate electrolytes is under mass transfer controlled conditions. This dependence of zinc on mass transfer is qualitatively seen in Fig. 3, where the area under the zinc dissolution curve increases with an increase in sweep rate thereby indicating that more material is deposited during the cathodic sweep cycle as the electrode rotation speed increases.

Potentiodynamic stripping curves recorded in solutions containing $0.5 \mathrm{M} \mathrm{NiSO}_{4}+0.5 \mathrm{M} \mathrm{Na}_{2} \mathrm{SO}_{4}, \mathrm{pH} 2.5$ are shown in Fig. 4. Nickel film was electrodeposited using copper rotating disc electrodes at $v=30 \mathrm{mV} \mathrm{s}^{-1}$ and at different electrode rotation rates. In the cathodic sweep, there was no significant increase in current up to $-0.9 \mathrm{~V} v s$. SCE. This indicates that nickel deposition occurs at a much more cathodic potential than its standard reduction potential. This is similar to the observation made by Lin and Selman ${ }^{15}$ for the electrodeposition of nickel from chloride electrolytes. A distinct current peak at $E_{\mathrm{pa}}=-0.19 \mathrm{~V}$ vs. SCE for dissolution of nickel appears on the anodic branch of the curve. Increasing the electrode rotation speed from $\omega=200$ to $1000 \mathrm{rpm}$ causes the anodic peak area to decrease, indicating that the nickel deposition process from sulfate electrolytes is not mass transfer controlled, which is in agreement with the mechanism of single metal deposition of nickel suggested by Matulis and Slizys. ${ }^{25}$ The actual decrease in the peak area during the deposition of nickel can be attributed to the mass transfer dependence of the competing proton reduction reaction. $\mathrm{H}^{+}$ ion transfer from the bulk to the electrode surface is the con- 


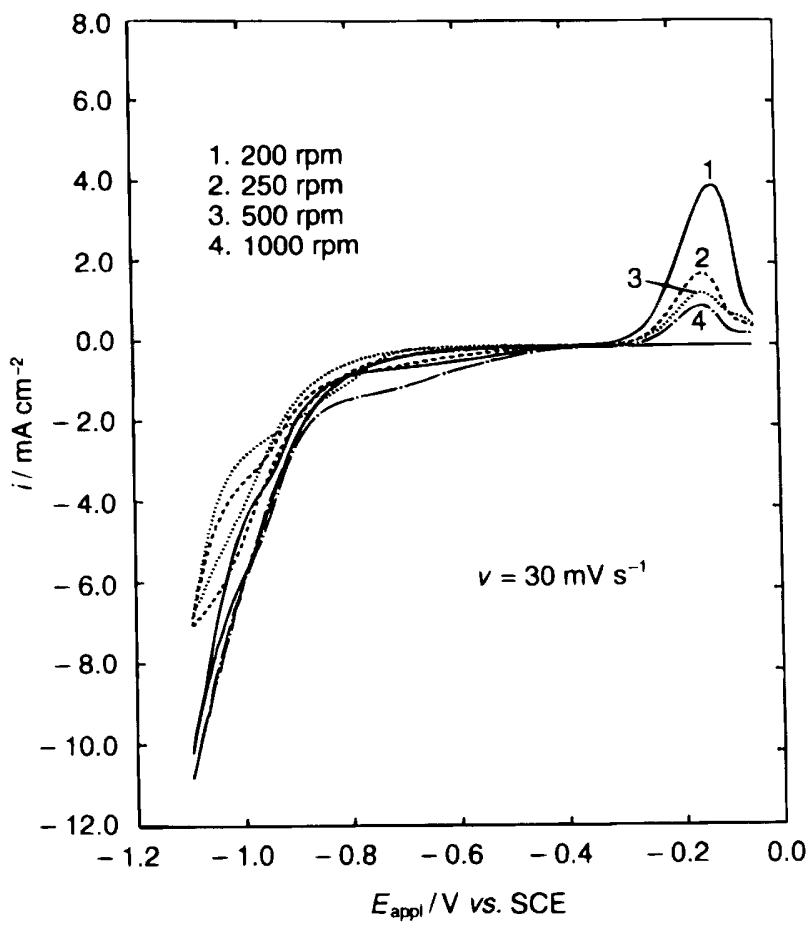

Fig. 4 Potentiodynamic stripping voltammograms of nickel film electrodeposited from electrolyte containing $0.5 \mathrm{M} \mathrm{NiSO}_{4}+0.5 \mathrm{M}$ $\mathrm{Na}_{2} \mathrm{SO}_{4}, \mathrm{pH} 2.5, v=30 \mathrm{mV} \mathrm{s}^{-1}$ at different rotation speeds

trolling factor in the proton reduction reaction. ${ }^{15}$ For a given electrode potential and a fixed scan rate, increasing the electrode rotation speed causes more $\mathrm{H}^{+}$ions to be present near the electrode surface as can be seen from the increase in the cathodic current as a function of electrode rotation speed. This causes the current density for the nickel deposition reaction to diminish at higher rotation speeds, thereby causing the anodic peak area for nickel dissolution to decrease.

Linear sweep voltammograms recorded on fixed copper disc electrodes from electrolytes containing $0.5 \mathrm{M} \mathrm{NiSO}_{4}+0.2$ м $\mathrm{ZnSO}_{4}+0.5 \mathrm{M} \mathrm{Na}_{2} \mathrm{SO}_{4}$ for different sweep rates are shown in Fig. 5. The curve for a sweep rate of $250 \mathrm{mV} \mathrm{s}^{-1}$ shows two well defined current peaks on the anodic branch. A broad peak at $E_{1 \mathrm{pa}}=-0.7 \mathrm{~V} v \mathrm{~s}$. SCE and a second peak at $E_{2 \mathrm{pa}}=$ $-0.24 \mathrm{~V} v \mathrm{~s}$. SCE are observed. The peak at $-0.7 \mathrm{~V} v \mathrm{~s}$. SCE is more positive than the zinc dissolution peak shown in Fig. 3. The anodic peak at $-0.24 \mathrm{~V}$ vs. SCE corresponds to that of nickel dissolution which is slightly more cathodic than obtained in Fig. 4. The LSVs obtained when both metals are present in the solution (Fig. 5) are different from those formed by superposition of the ones obtained from the electrolytes containing pure zinc and nickel ions (Fig. 3 and 4) indicating that an interaction between the two deposition processes and deposited metals does exist. The dissolution peak potential of zinc being more positive than that of pure metal ions may result from a significant free energy change upon mixing zinc and nickel in the solid phase or the formation of intermediate phases in the case of zinc-nickel alloys. At higher sweep rates the zinc peak at $-0.7 \mathrm{~V}$ vs. SCE splits into two distinct ones. A sharp peak occurs at $E_{1 \mathrm{pa}}=-0.7 \mathrm{~V} v \mathrm{~s}$. SCE and another at $-0.575 \mathrm{~V}$ vs. SCE. The zinc content in deposited zinc-nickel alloys in Fig. 5 varied from 84 to $91 \%$. According to the zincnickel phase diagram ${ }^{26}$ an alloy with a zinc content between 84 and $92 \%$ is characterized at low temperatures with two intermediate phases, $\gamma$ and $\delta$, respectively. In Fig. 6 , the anodic branch of the LSVs possesses two peaks which could be ascribed to the dissolution of zinc from the two intermediate phases. The first anodic peak $\left(E_{1 \mathrm{pa}}=-0.7 \mathrm{~V}\right.$ vs. SCE) corresponds to zinc dissolution from the zinc rich $\delta$ phase $(90 \%$

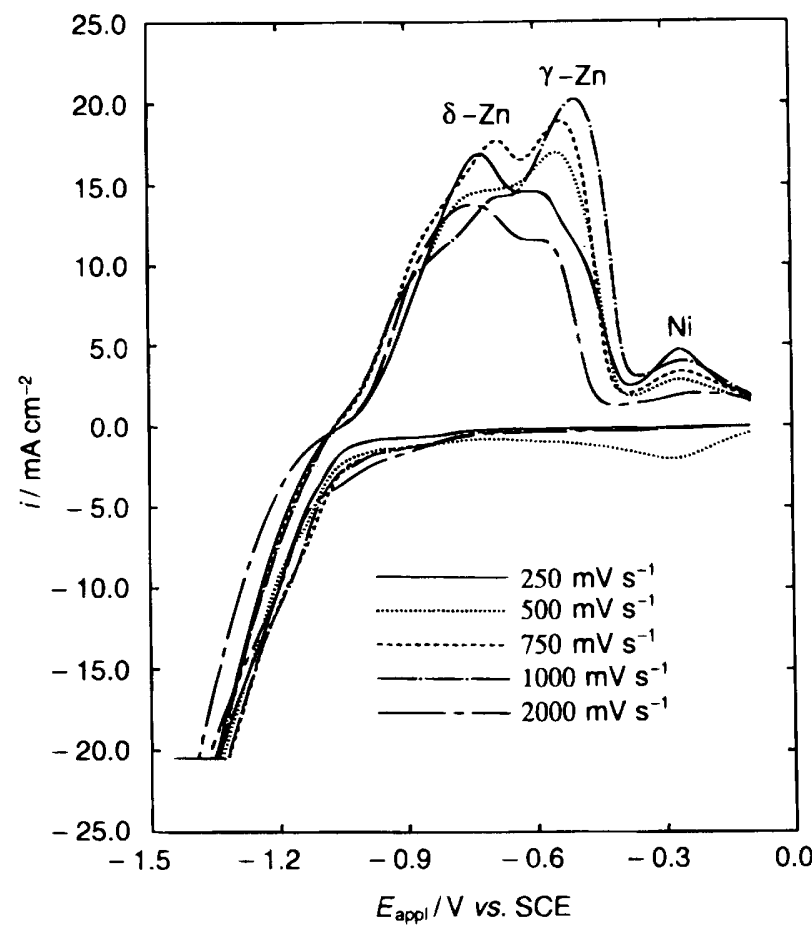

Fig. 5 Potentiodynamic stripping voltammograms recorded on a fixed disc electrode from electrolytes containing $0.5 \mathrm{M} \mathrm{NiSO}_{4}+0.2 \mathrm{M}$ $\mathrm{ZnSO}_{4}+0.5 \mathrm{M} \mathrm{Na}_{2} \mathrm{SO}_{4}, \mathrm{pH} 2.5$ at different sweep rates

$\mathrm{Zn})$. The second peak which occurs at $-0.575 \mathrm{~V}$ vs. SCE corresponds to dissolution of zinc from the $\gamma$ phase (zinc content varies between 76 and $87 \%$ ). The small difference in the chemical potential of zinc in the two phases is due to the small difference in the nickel content in the alloy. Since the electrodeposition of zinc is under mass transfer control ${ }^{22,27}$ one can expect that at a constant sweep rate, an alloy rich in zinc will be electrodeposited and subsequently stripped at higher rotation rates. Indeed this phenomenon was observed in Fig. 6

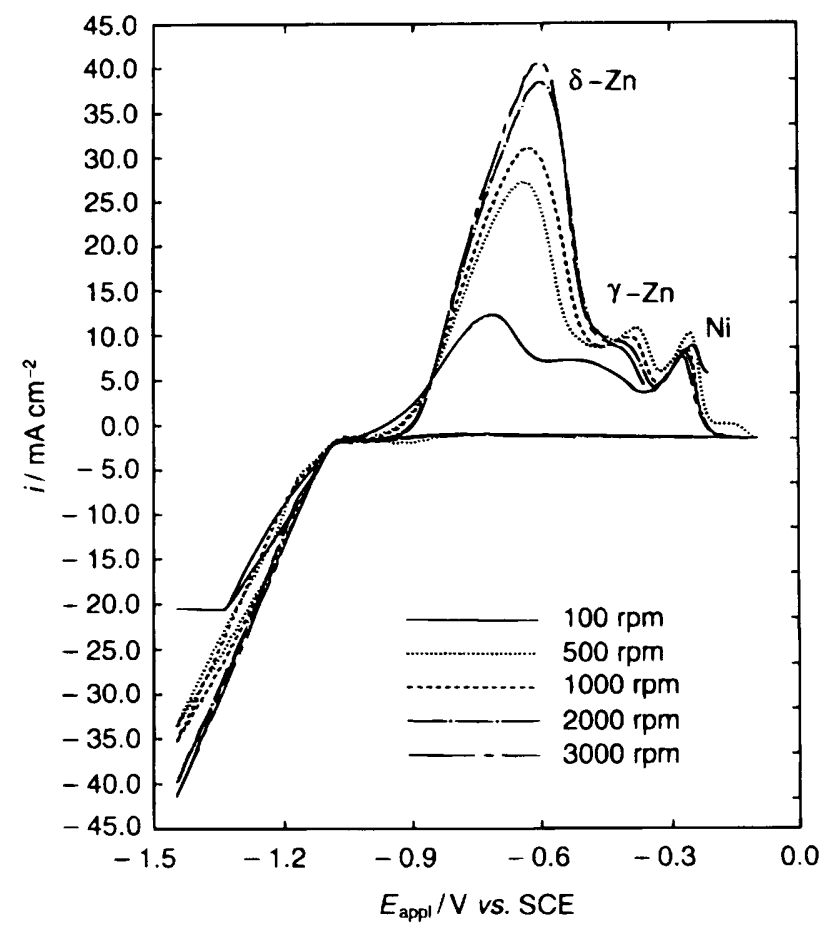

Fig. 6 Potentiodynamic stripping voltammograms obtained in the same electrolyte as in Fig. 5 for different rotation speeds, $v=30 \mathrm{mV}$ $\mathrm{s}^{-1}$ 
where potentiodynamic stripping voltammograms were obtained from previously electrodeposited zinc-nickel alloys on copper rotating disc electrodes at a constant sweep rate of $20 \mathrm{mV} \mathrm{s}^{-1}$ and for different rotation speeds. As shown in Fig. 6 , by increasing the rotation speed of the copper disc electrode, the content of the intermediate phase rich in zinc $(\delta)$ increases in the alloy, while the content of the $\gamma$ phase decreases. The third peak observed in Fig. 6 is that of the dissolution of nickel. Similar to those obtained in Fig. 4, the nickel dissolution peak again decreases with an increase in the electrode rotation speed. This can again be explained by the presence of mass transfer dependent competing reactions, in this case both hydrogen evolution and zinc reduction reactions.

\section{Galvanostatic dc, pulse and pulse reverse plating of $\mathrm{Zn}-\mathrm{Ni}$ alloys}

Galvanostatic pulse and pulse reverse plating of zinc-nickel alloys were carried out in the presence and absence of nonyl phenyl polyethylene oxide. Fig. 7 shows the zinc content of deposits obtained using dc deposition. The plating was carried out from an electrolyte containing $0.5 \mathrm{M} \mathrm{NiSO}_{4}+0.2 \mathrm{M}$ $\mathrm{ZnSO}_{4}+0.5 \mathrm{M} \mathrm{Na}_{2} \mathrm{SO}_{4}$ at a pH of 2.5 at $50^{\circ} \mathrm{C}$. The zinc content in the deposit was determined for different electrode rotation rates as a function of the applied cathodic current density. By proper choice of the current density and the agitation conditions, alloy compositions were obtained with a zinc content between 82 and $91 \%$. A maximum zinc content in the alloy is observed in Fig. 7 for all rotation speeds. The maximum shifts in the direction of higher current densities as the rotation speed of the electrode increases, indicating masstransfer controlled conditions for zinc deposition. Similar behaviour has been observed by Andricacos et $a .^{28}$ for the deposition of $\mathrm{Fe}-\mathrm{Ni}$ alloys.

Fig. 8 shows the composition of zinc-nickel films plated on the rotating disc electrodes as a function of the average current density for different rotation speeds in the pc mode. The deposition was carried out using pulse plating with a duty cycle of 0.5 and frequency of $80 \mathrm{~Hz}$ at $50^{\circ} \mathrm{C}$. The composition of the electrolyte was the same as in Fig. 7. At lower average current densities, the zinc deposition is under kinetic control

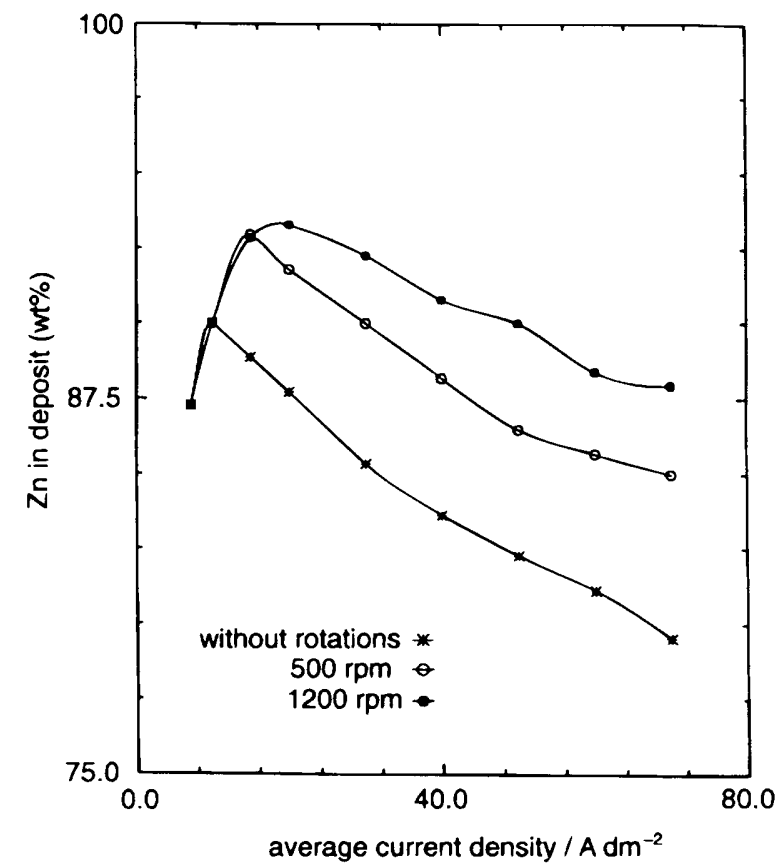

Fig. 7 Composition of a dc plated $\mathrm{Zn}-\mathrm{Ni}$ alloy from the same electrolyte as in Fig. 5 as a function of the applied current density at several electrode rotation speeds (wt.\%)

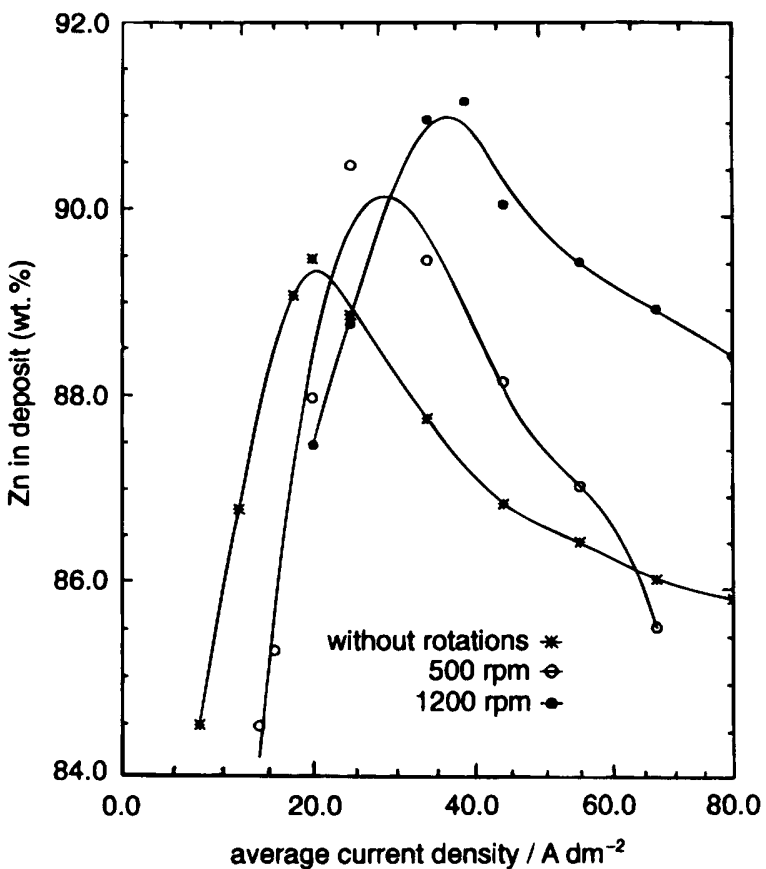

Fig. 8 Zinc composition profiles as a function of current density at various rotation speeds for pc mode

and the zinc content in the alloy increases with increasing current density. As shown in Fig. 8, the zinc content reaches a maximum and then decreases with increasing current density due to the hydrogen evolution being under mass transfer control. The position of the maximum observed in Fig. 8 shifts to higher current densities with increase in electrode rotation speed. As expected, at higher rotation speeds, the limiting current is attained at higher current densities. The peak potential $E_{\mathrm{p}}$ at high current densities increases to a sufficiently negative value so that the mass-transfer limitation is the major factor determining the zinc content in the alloy causing a flattening of zinc content in the zinc composition profiles. During $t_{\text {off }}$, in the pc mode, zinc dissolves at the same rate as the hydrogen discharge reaction to maintain a zero current. In other words, the mixed electrode potential is between the open circuit potential of $\mathrm{H}_{2} / \mathrm{H}^{+}$and $\mathrm{Zn} / \mathrm{Zn}^{2+}$ which is anodic for zinc thus causing dissolution of insignificant amounts of zinc.

Fig. 9 shows the zinc composition vs. average current density at various electrode rotation speeds for pulse reverse mode. The zinc content in the alloy is lower for the pr mode compared with the zinc content values obtained in the pc mode. In the pr mode, the anodic current $\left(i_{\mathrm{r}}=-0.2 i_{\mathrm{p}}\right)$ during $t_{\text {off }}$ causes some of the zinc in the alloy to dissolve. Since nickel is passivated during the anodic process in a sulfate bath, the pr mode affects the zinc dissolution more than nickel dissolution. As seen in Fig. 9 for the pr mode, the zinc content in the alloy decreases with increasing rotation speed. The $\mathrm{pr}$ mode yields more anodic $E_{\mathrm{r}}$ during the relaxation period compared to the pc mode under the same $i_{\mathrm{p}}$. Consequently, for the pr mode at high rotation speeds, the proton depletion will be less severe at the end of $t_{\mathrm{on}}$. Higher concentrations of $\mathrm{H}^{+}$at the end of $t_{\text {on }}$ will cause the oxidation of $\mathrm{H}_{2}$ to occur at a lower rate during $t_{\text {off }}$, which induces a more anodic potential for a given $i_{\mathrm{r}}$, which favours the zinc dissolution reaction.

Fig. 10 shows the effect of nonyl phenyl polyethylene oxide on the alloy composition. Adsorption of nonyl phenyl polyethylene oxide on the electrode surface was expected to increase the surface overpotential due to the less effective exchange current density of the electroactive species participating in the reduction process. At a specific applied current density, the fractional coverage of the electrode surface with nonyl phenyl polyethylene oxide causes the operating poten- 


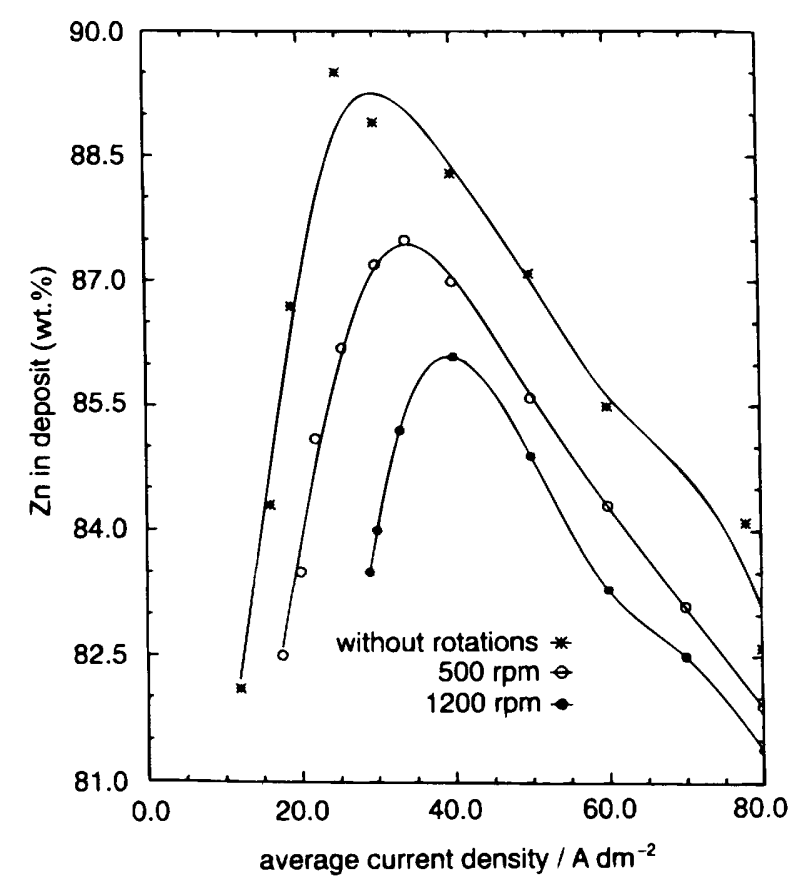

Fig. 9 Zinc composition profiles as a function of current density at various rotation speeds for $\mathrm{pr}$ mode

tial to be extended in either a cathodic or anodic direction without creating conditions for concentration depletion of the electroactive species at the interface. This is clearly seen in Fig. 10 , where for the pc mode, the hump of the zinc concentration profile shifts to a more cathodic current indicating that the mass transfer limitations for zinc reduction are delayed. For the pr mode, the presence of $2 \mathrm{~g}^{-1}$ of nonyl phenyl polyethylene oxide in the electrolyte reduces the zinc content in the alloy due to the additive surface-coverage effect. In this case the hydrogen ion concentration is less depleted during $t_{\text {on }}$ because of the reduction in available surface area for hydrogen evolution reaction. Higher proton concentration during the $t_{\text {off }}$ period and a smaller surface reaction area decrease the rate of the hydrogen oxidation reaction which causes, for a specific applied average current density, the electrode to be

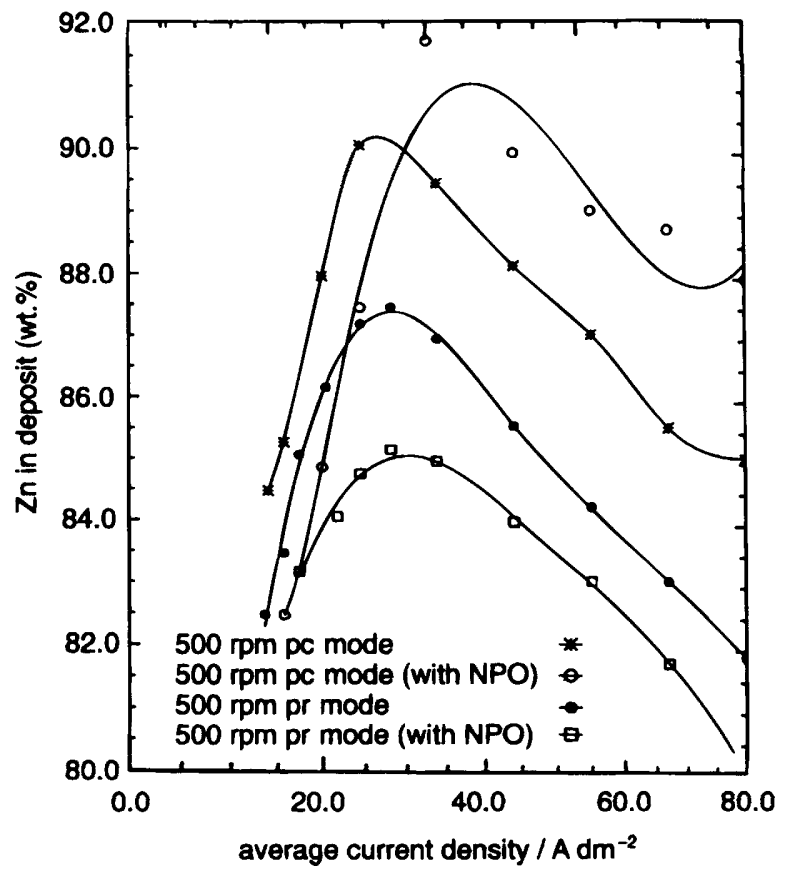

Fig. 10 Effect of nonyl phenyl polyethylene oxide on the alloy composition polarized to a more anodic potential which favours the zinc dissolution reaction.

Fig. 11 shows the pulse potential responses obtained at 500 rpm for different applied current densities. The galvanostatic pulse and pulse reverse experiments were carried out in sulfate electrolytes in the presence and absence of $2 \mathrm{~g}^{-1}$ nonyl phenyl polyethylene oxide. As shown in Fig. 11, the pc mode induces a more cathodic potential than the pr mode. This phenomenon can be explained by taking into account the fact that in the pc mode higher proton concentration and $\mathrm{Zn}^{2+}$ depletion is observed during $t_{\text {on }}$ because less replenishment of these electroactive species occurs during $t_{\text {off }}$ compared to the pr mode. In the pr mode, enforced dissolution of $\mathrm{Zn}^{2+}$ and proton production are present in the relaxation period. As shown in Fig. 11, in the low average current density region, the difference in pulse potential responses in $\mathrm{pc}$ and $\mathrm{pr}$ modes is not significant.

In the presence of $2 \mathrm{~g}^{-1}$ nonyl phenyl polyethylene oxide in the electrolyte an enhanced polarization is observed which is more pronounced in the pc compared to the pr mode. The increased polarization is caused by the reduced available reactive area due to electrode coverage by nonyl phenyl polyethylene oxide. The increased polarization under potentiostatic conditions in the presence of organic additives has been explained theoretically. ${ }^{30}$ Slower kinetics rather than the concentration overpotential compensate for the potential drop which occurs in the presence of surface-active agents in the electrolyte.

The partial current efficiency for zinc sharply increases with increasing current density and levels off at 59 to $64 \%$. Zinc partial current efficiency is also dependent on the electrode rotation rate. A small decrease in zinc partial current efficiency was observed with an increase in agitation from $\omega=0$ to $1200 \mathrm{rpm}$ due to the parasitic hydrogen evolution reaction, which is under mass-transport control. Nickel partial current efficiency gradually increases with increase in the average current density, levels off at 9.5 to $12.8 \%$ and is independent of agitation of the electrode.

\section{Surface analysis}

To study the influence of rotation speed of the electrode on the morphology of the electrodeposited zinc-nickel alloys,

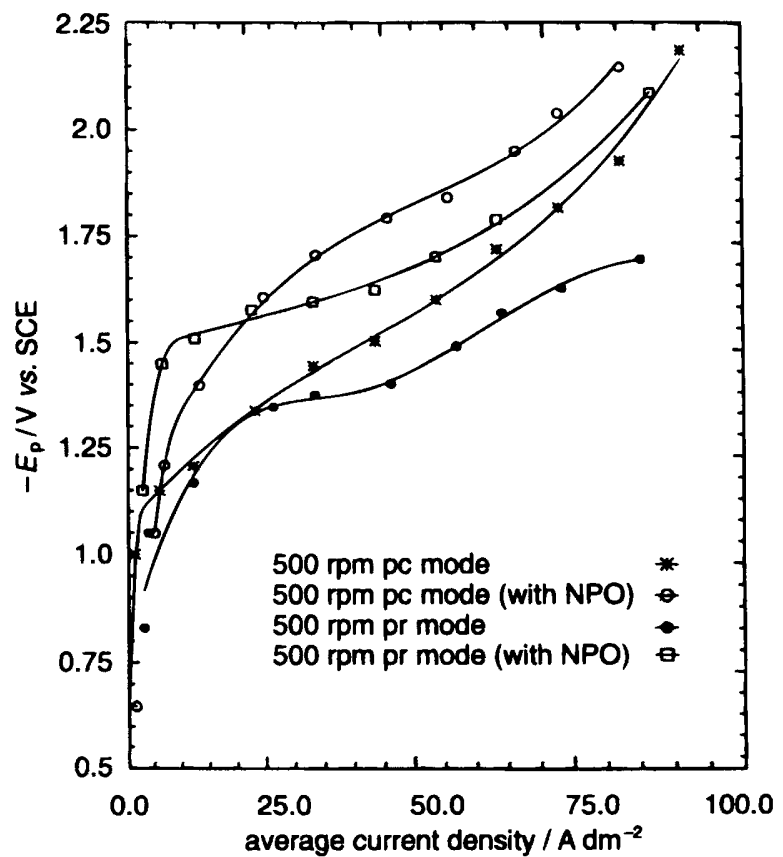

Fig. 11 Pulse potential responses at different applied current densities during $t_{\text {on }}$ 

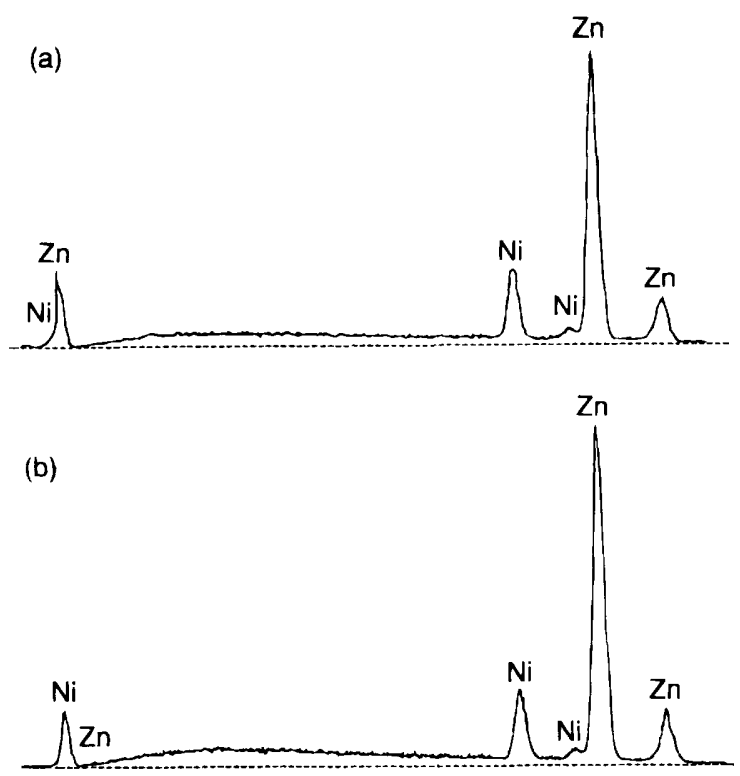

Fig. 12 EDS spectrum of samples taken at an average current density of $50 \mathrm{~A} \mathrm{dm}^{-2}$ on a rotating copper disc electrode and at rotation speeds of (a) 100 and (b) $1200 \mathrm{rpm}$

investigations were carried out using SEM and EDS. The zinc-nickel alloys were plated galvanostatically from electrolytes containing $0.5 \quad \mathrm{M} \quad \mathrm{NiSO}_{4}+0.2 \quad \mathrm{M} \quad \mathrm{ZnSO}_{4}+0.5 \mathrm{M}$ $\mathrm{Na}_{2} \mathrm{SO}_{4}$. The deposition was carried out on fixed rotating copper disc electrodes at two different electrode rotation speeds, $\omega=100$ and $1200 \mathrm{rpm}$. An EDS spectrum of zincnickel alloys plated by using current density of $50 \mathrm{~A} \mathrm{dm}^{-2}$ and rotation speeds of 500 and $1200 \mathrm{rpm}$ are shown in Fig. 12 The zinc contents in the alloys were 88.1 and $90.8 \%$, respectively. The same phenomenon was observed in Fig. 6, which shows potentiodynamic stripping curves recorded at different electrode rotation speeds. Increasing the electrode rotation speed causes the zinc content in the alloy to increase. At high rotation speeds, a zinc rich $(90 \% \mathrm{Zn}) \delta$ phase is formed.

The influence of the organic additive on the morphology of the electrodeposited zinc-nickel alloys was studied using incident light microscopy and incident interference microscopy. The zinc-nickel alloy was deposited using the sulfate electrolyte $+2 \mathrm{~g} \mathrm{l}^{-1}$ nonyl phenyl polyethylene oxide, $\mathrm{pH} 2.5$ and $T=50^{\circ} \mathrm{C}$. The results obtained for zinc-nickel electrodeposition are summarized in Fig. 13. The zinc-nickel alloy shows dendritic crystal growth when electrodeposited from

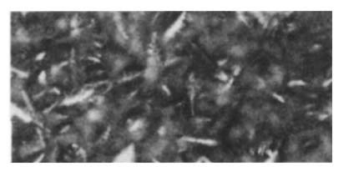

(a)

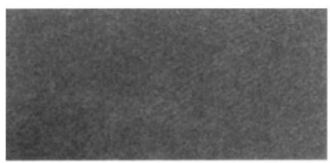

(c)

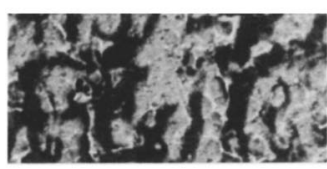

(b)

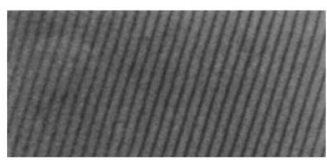

(d)
Fig. 13 Metallographic pictures of the electrodeposited $\mathrm{Zn}-\mathrm{Ni}$ alloy, magnification $\times 100$. (a) Dendritic growth in the absence of nonyl phenyl polyethylene oxide, $I=12 \mathrm{~A} \mathrm{dm}^{-2}$; (b) morphology of deposited zinc-nickel alloy in the presence of $2 \mathrm{~g} \mathrm{l}^{-1}$ nonyl phenyl polyethylene oxide, $I=12 \mathrm{~A} \mathrm{dm}^{-2}$; (c) interference metallographic picture of the same place as in Fig. 13(b); (d) interference metallographic picture obtained at optimal plating conditions using a current density of $I=15 \mathrm{~A} \mathrm{dm}^{-2}$ and $2 \mathrm{~g}^{-1}$ nonyl phenyl polyethylene oxide.

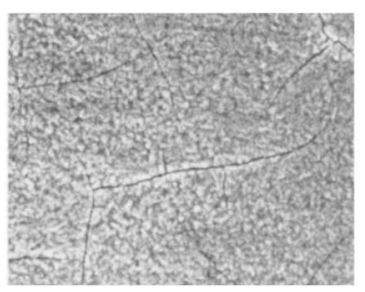

(a)

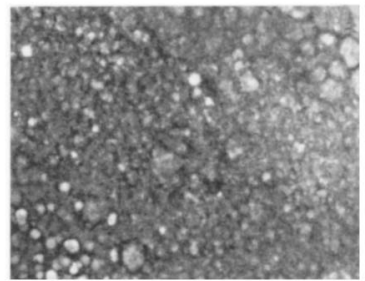

(c)

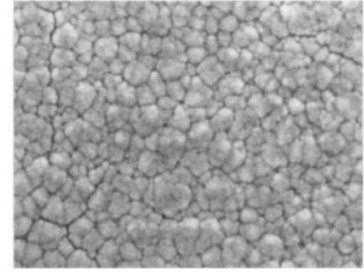

(b)

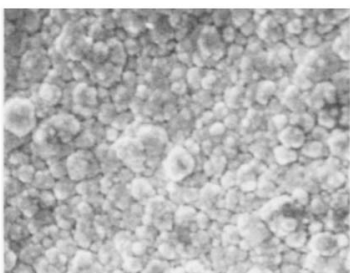

(d)

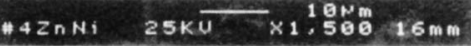

Fig. 14 SEMs of an alloy deposited from a bath containing $0.5 \mathrm{M}$ $\mathrm{NiSO}_{4}+0.2 \mathrm{M} \mathrm{ZnSO}_{4}+0.5 \mathrm{M} \mathrm{Na}_{2} \mathrm{SO}_{4}+2 \mathrm{~g} \mathrm{l}^{-1}$ nonyl phenyl polyethylene oxide, $\mathrm{pH} 2.5, T=50^{\circ} \mathrm{C}$ (a) using the galvanostatic pulse technique, average current density $I_{\mathrm{av}}=-60 \mathrm{~A} \mathrm{dm}^{-2}$ at $\omega=500$ $\mathrm{rpm}$; (b) using the galvanostatic pulse technique, average curren density $I_{\mathrm{ay}}=-40 \mathrm{~A} \mathrm{dm}^{-2}$, (c) using the galvanostatic pulse reverse technique, $I_{\mathrm{av}}=-60 \mathrm{~A} \mathrm{dm}^{-2}, i_{\mathrm{r}}=12 \mathrm{~A} \mathrm{dm}^{-2}$ at $\omega=500 \mathrm{rpm}$; and (d) using the galvanostatic pulse reverse technique, $I_{\mathrm{av}}=-40 \mathrm{~A}$ $\mathrm{dm}^{-2}, i_{\mathrm{r}}=8 \mathrm{~A} \mathrm{dm}^{-2}$ at $\omega=500 \mathrm{rpm}$

baths without organic additives, shown in Fig. 13(a). Addition of nonyl phenyl polyethylene oxide even in small quantities (50 $\mathrm{mg} \mathrm{1}^{-1}$ ) remarkably changes the morphology of the deposit Fig. 13(b). The surface becomes brighter and the marks of the dendritic growth disappear. The concentration of the organic additive is not the only factor determining the deposit morphology. Other factors, such as current density and bath temperature, also contribute to the deposit morphology change. This phenomenon is illustrated in Fig. 13(c) which shows the same place on the surface as in Fig. 13(b) but as an

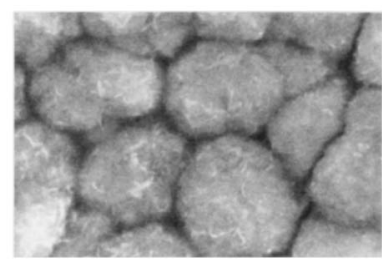

(a)

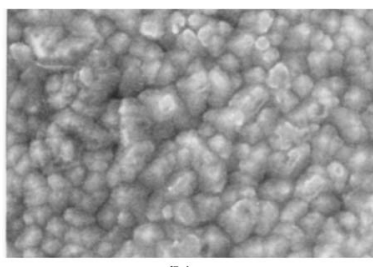

(b)

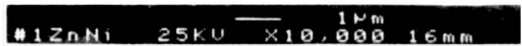

Fig. 15 SEM spectrum of an alloy deposited using the pulse reverse technique from a bath containing $0.5 \mathrm{M} \mathrm{NiSO}_{4}+0.2 \mathrm{M} \mathrm{ZnSO}_{4}+0.5$ M $\mathrm{Na}_{2} \mathrm{SO}_{4}, \mathrm{pH} 2.5, T=50^{\circ} \mathrm{C}, \omega=500 \mathrm{rpm}$; (a) in the absence of nonyl phenyl polyethylene oxide, average current density $I_{\mathrm{a}}=-40 \mathrm{~A}$ $\mathrm{dm}^{-2}, i_{\mathrm{r}}=8 \mathrm{~A} \mathrm{dm}^{-2}$ and (b) in the presence of $2 \mathrm{~g}^{-1}$ nonyl phenyl polyethylene oxide, average current density, $I_{\mathrm{a}}=-40 \mathrm{~A} \mathrm{dm}^{-2}, i_{\mathrm{r}}=8$ A dm ${ }^{-2}$ 
interference metallographic picture. The interference lines are not completely straight, showing that bright and smooth deposits are not formed over the whole surface. When the optimal current density $\left(I=15 \mathrm{~A} \mathrm{dm}^{-2}\right)$ is applied and the electrodeposition is carried out using the sulfate electrolyte $+2 \mathrm{~g} \mathrm{l}^{-1}$ nonyl phenyl polyethylene oxide, a mirror bright deposit is obtained over the whole surface, and as shown in Fig. 13(d) the interference lines are completely straight.

Typical SEM micrographs of samples prepared by galvanostatic pulse and pulse reverse modes are shown in Fig. 14. For the pc mode under low rotation speeds and high average current density, the deposits were cracked. Cracking is caused by the relaxation of metal hydrides which are the product of the hydrogen evolution reaction. ${ }^{29}$ For the pc mode when low average current densities were used for alloy deposition, the deposit grain size decreased and the deposit was not cracked.

By reducing the average current density and by increasing the rotation speed one can use the pr mode to deposit a zincnickel alloy without craçks. As shown in Fig. 14, the deposit grain size increases when the pr mode was used as an alloy deposition technique. The observed increase in the deposit grain size may be explained as follows. According to Puippe ${ }^{30}$ the crystal nucleation rate, which is inversely proportional to the deposit grain size, is enhanced by increasing the overpotentials. Since the pr mode induces a less cathodic potential than $\mathrm{pc}$ mode due to the higher solution concentration in the vicinity of the electrode, the pr technique has a higher crystal growth rate than the pc plating technique.

In Fig. 15, the pulse reversal technique was used to deposit a zinc-nickel alloy using an average current density of $I_{\mathrm{av}}=$ $-40 \mathrm{~A} \mathrm{dm}^{-2}, i_{\mathrm{r}}=3.0 \mathrm{~A} \mathrm{dm}^{-2}$ and a rotation speed of 500 $\mathrm{rpm}$. The deposition was carried out from an electrolyte containing: $0.5 \mathrm{M} \mathrm{NiSO}_{4}+0.05 \mathrm{M} \mathrm{ZnSO}_{4}$ in the presence and absence of nonyl phenyl polyethylene oxide at $50^{\circ} \mathrm{C}$. As shown in Fig. 15, the levelling effect is evident for zinc-nickel deposits electrodeposited from the bath which contained nonyl phenyl polyethylene oxide.

\section{Conclusion}

The codeposition of zinc-nickel alloys in the presence of nonyl phenyl polyethylene oxide is explained taking into account zinc-nickel plating bath solution chemistry, mass transfer of ionic species and electrode surface reactions. Linear sweep voltammetry was used as an in situ technique to characterize thin layers of zinc-nickel alloys. The zinc dissolution potentials from zinc-nickel deposits were found to be more positive than those of the pure metal ions due to formation of two zinc-nickel intermediate phases $\gamma$ and $\delta$ respectively. Galvanostatic pulse and pulse reverse techniques were used to study the plating of zinc-nickel alloys in the presence of nonyl phenyl polyethylene oxide. At low applied average current densities in $\mathrm{pc}$ and pr mode, the zinc deposition is under kinetic control and an increase of the polarization increases the zinc content in the deposit. For the pc mode at low average current densities the main electrode reactions are nickel deposition and hydrogen evolution. In this region the zinc content decreases as the rotation speed increases. Limitation due to mass transfer becomes more important at higher average current densities. At this region, higher electrode rotation speeds correspond to larger zinc contents in the deposit. The applied anodic current during $t_{\text {off }}$ in the pr mode forces more anodic potentials compared with the pc mode which favours the zinc dissolution. The role of nonyl phenyl polyethylene oxide on zinc-nickel codeposition was explained by the effect of surface coverage.

Financial support from AESF under research Project RF-93 is gratefully acknowledged.

\section{Appendix}

The solution consisting of $0.5 \mathrm{M} \mathrm{NiSO}_{4}, 0.2 \mathrm{M} \mathrm{ZnSO}_{4}$ and 0.5 $\mathrm{M} \mathrm{Na}_{2}(\mathrm{SO})_{4}$ can be divided into three regions as a function of $\mathrm{pH}$ : (a) region without precipitation of either $\mathrm{Zn}(\mathrm{OH})_{2}$ or $\mathrm{Ni}(\mathrm{OH})_{2} ;(b)$ region in which only $\mathrm{Zn}(\mathrm{OH})_{2}$ precipitates and (c) region where both $\mathrm{Zn}(\mathrm{OH})_{2}$ and $\mathrm{Ni}(\mathrm{OH})_{2}$ precipitate.

\section{Region (a)}

The variables to be determined are $\left[\mathrm{Zn}^{2+}\right],\left[\mathrm{Zn}(\mathrm{OH})^{+}\right]$, $\left[\mathrm{Zn}_{2}(\mathrm{OH})^{3+}\right],\left[\mathrm{Ni}^{2+}\right],\left[\mathrm{Ni}(\mathrm{OH})^{+}\right],\left[\mathrm{OH}^{-}\right],\left[\mathrm{HSO}_{4}^{-}\right]$, $\left[\mathrm{SO}_{4}^{2-}\right],\left[\mathrm{H}_{2} \mathrm{O}\right],\left[\mathrm{H}_{2} \mathrm{SO}_{4}\right]_{\mathrm{ad}}$ or $[\mathrm{NaOH}]_{\mathrm{ad}}$, where $[i]_{\mathrm{ad}}$ is the concentration of species added to the solution. The equations used to determine the concentrations are: material balance on zinc,

$$
\left[\mathrm{ZnSO}_{4}\right]_{\mathrm{ad}}=\left[\mathrm{Zn}^{2+}\right]+\left[\mathrm{Zn}(\mathrm{OH})^{+}\right]+2\left[\mathrm{Zn}_{2}(\mathrm{OH})^{3+}\right]
$$

material balance on nickel,

$$
\left[\mathrm{NiSO}_{4}\right]_{\mathrm{ad}}=\left[\mathrm{Ni}^{2+}\right]+\left[\mathrm{Ni}(\mathrm{OH})^{+}\right]
$$

material balance on sulfate,

$\left[\mathrm{NiSO}_{4}\right]_{\mathrm{ad}}+\left[\mathrm{ZnSO}_{4}\right]_{\mathrm{ad}}+\left[\mathrm{Na}_{2} \mathrm{SO}_{4}\right]_{\mathrm{ad}}$

$$
+\left[\mathrm{H}_{2} \mathrm{SO}_{4}\right]_{\mathrm{ad}}=\left[\mathrm{HSO}_{4}{ }^{-}\right]+\left[\mathrm{SO}_{4}{ }^{2-}\right]
$$

(where $\left[\mathrm{H}_{2} \mathrm{SO}_{4}\right]_{\mathrm{ad}}$ is a variable), material balance on oxygen,

$$
\begin{gathered}
{\left[\mathrm{H}_{2} \mathrm{O}_{\mathrm{ad}}+4\left[\mathrm{Na}_{2} \mathrm{SO}_{4}\right]_{\mathrm{ad}}+4\left[\mathrm{NiSO}_{4}\right]_{\mathrm{ad}}+4\left[\mathrm{ZnSO}_{4}\right]_{\mathrm{ad}}\right.} \\
+4\left[\mathrm{H}_{2} \mathrm{SO}_{4}\right]_{\mathrm{ad}}=\left[\mathrm{Zn}(\mathrm{OH})^{+}\right]+\left[\mathrm{Zn}_{2}(\mathrm{OH})^{3+}\right] \\
+\left[\mathrm{Ni}(\mathrm{OH})^{+}\right]+\left[\mathrm{OH}^{-}\right]+4\left[\mathrm{HSO}_{4}{ }^{-}\right]+4\left[\mathrm{SO}_{4}{ }^{2-}\right]
\end{gathered}
$$

electroneutrality,

$$
\sum_{i} z_{\mathrm{i}} c_{\mathrm{i}}=0
$$

and the equilibrium conditions:

$$
\begin{gathered}
{\left[\mathrm{Zn}^{2+}\right]\left[\mathrm{OH}^{-}\right]-K_{1}\left[\mathrm{Zn}(\mathrm{OH})^{+}\right]=0} \\
{\left[\mathrm{Zn}^{2+}\right]\left[\mathrm{OH}^{-}\right]^{3}-K_{3}\left[\mathrm{Zn}_{2}(\mathrm{OH})^{3+}\right]=0} \\
{\left[\mathrm{Ni}^{2+}\right]\left[\mathrm{OH}^{-}\right]-K_{4}\left[\mathrm{Ni}(\mathrm{OH})^{+}\right]=0} \\
{\left[\mathrm{H}^{+}\right]\left[\mathrm{SO}_{4}{ }^{2-}\right]-K_{6}\left[\mathrm{HSO}_{4}{ }^{-}\right]=0} \\
{\left[\mathrm{H}^{+}\right]\left[\mathrm{OH}^{-}\right]-K_{7}=0}
\end{gathered}
$$

\section{Region (b)}

The variables to be determined are $\left[\mathrm{Zn}^{2+}\right],\left[\mathrm{Zn}(\mathrm{OH})^{+}\right]$, $\left(\mathrm{Zn}(\mathrm{OH})_{2}\right], \quad\left[\mathrm{Zn}_{2}(\mathrm{OH})^{3+}\right],\left[\mathrm{Ni}^{2+}\right],\left[\mathrm{Ni}(\mathrm{OH})^{+}\right],\left[\mathrm{OH}^{-}\right]$, $\left[\mathrm{HSO}_{4}{ }^{-}\right],\left[\mathrm{SO}_{4}{ }^{2-}\right],\left[\mathrm{H}_{2} \mathrm{O}\right]$ and $[\mathrm{NaOH}]_{\mathrm{ad}}$. The equations used are: material balance on zinc,

$$
\begin{aligned}
{\left[\mathrm{ZnSO}_{4}\right]_{\mathrm{ad}}=} & {\left[\mathrm{Zn}^{2+}\right]+\left[\mathrm{Zn}(\mathrm{OH})^{+}\right] } \\
& +\left[\mathrm{Zn}(\mathrm{OH})_{2}\right]+2\left[\mathrm{Zn}_{2}(\mathrm{OH})^{3+}\right]
\end{aligned}
$$

material balance on nickel [eqn. (A2)], material balance on sulfate,

$$
\begin{gathered}
{\left[\mathrm{NiSO}_{4}\right]_{\mathrm{ad}}+\left[\mathrm{ZnSO}_{4}\right]_{\mathrm{ad}}+\left[\mathrm{Na}_{2} \mathrm{SO}_{4}\right]_{\mathrm{ad}}} \\
=\left[\mathrm{HSO}_{4}{ }^{-}\right]+\left[\mathrm{SO}_{4}{ }^{2-}\right]
\end{gathered}
$$

material balance on oxygen,

$$
\begin{aligned}
& {\left[\mathrm{H}_{2} \mathrm{O}\right]_{\mathrm{ad}}+4\left[\mathrm{Na}_{2} \mathrm{SO}_{4}\right]_{\mathrm{ad}}+4\left[\mathrm{NiSO}_{4}\right]_{\mathrm{ad}}+4\left[\mathrm{ZnSO}_{4}\right]_{\mathrm{ad}}} \\
& +[\mathrm{NaOH}]_{\mathrm{ad}}=\left[\mathrm{Zn}(\mathrm{OH})^{+}\right]+2\left[\mathrm{Zn}(\mathrm{OH})_{2}\right]+\left[\mathrm{Zn}_{2}(\mathrm{OH})^{3+}\right] \\
& \quad+\left[\mathrm{Ni}(\mathrm{OH})^{+}\right]+\left[\mathrm{OH}^{-}\right]+4\left[\mathrm{HSO}_{4}{ }^{-}\right]+4\left[\mathrm{SO}_{4}{ }^{2-}\right](\mathrm{A} 13)
\end{aligned}
$$

electroneutrality [eqn. (A5)], and the equilibrium conditions, eqn. (A6)-(A10) and

$$
\left[\mathrm{Zn}^{2+}\right]\left[\mathrm{OH}^{-}\right]^{2}-K_{2}=0
$$


Table 1 Equilibrium constants and solubility products

\begin{tabular}{ccc}
\hline reaction $j$ & constant & ref. \\
\hline 1 & $1.10 \times 10^{5} \mathbf{M}^{-1}$ & 31 \\
4 & $1.99 \times 10^{5}$ & 31 \\
5 & $1.38 \times 10^{4} \mathbf{M}^{-1}$ & 31 \\
8 & $8.33 \times 10^{1} \mathbf{M}^{-1}$ & 32 \\
9 & $1.10 \times 10^{14} \mathbf{M}^{-2}$ & 32 \\
2 & $7.3 \times 10^{-17} \mathbf{M}^{2 a}$ & 33 \\
6 & $1.6 \times 10^{-14} \mathrm{M}^{2 a}$ & 33 \\
\hline
\end{tabular}

${ }^{a}$ Solubility product.

\section{Region (c)}

The variables to be determined are $\left[\mathrm{Zn}^{2+}\right],\left[\mathrm{Zn}(\mathrm{OH})^{+}\right]$, $\left[\mathrm{Zn}(\mathrm{OH})_{2}\right],\left[\mathrm{Zn}_{2}(\mathrm{OH})^{3+}\right],\left[\mathrm{Ni}^{2+}\right],\left[\mathrm{Ni}(\mathrm{OH})^{+}\right],\left[\mathrm{Ni}(\mathrm{OH})_{2}\right]$, $\left[\mathrm{OH}^{-}\right],\left[\mathrm{HSO}_{4}{ }^{-}\right],\left[\mathrm{SO}_{4}{ }^{2-}\right],\left[\mathrm{H}_{2} \mathrm{O}\right]$ and $[\mathrm{NaOH}]_{\mathrm{ad}}$. The equations used are: material balance on zinc [eqn. (A11)], material balance on nickel,

$$
\left[\mathrm{NiSO}_{4}\right]_{\mathrm{ad}}=\left[\mathrm{Ni}^{2+}\right]+\left[\mathrm{Ni}(\mathrm{OH})^{+}\right]+\left[\mathrm{Ni}(\mathrm{OH})_{2}\right]
$$

material balance on sulfate [eqn. (A12)], material balance on oxygen,

$$
\begin{aligned}
{\left[\mathrm{H}_{2} \mathrm{O}_{\mathrm{ad}}\right.} & +4\left[\mathrm{Na}_{2} \mathrm{SO}_{4}\right]_{\mathrm{ad}} 4+\left[\mathrm{NiSO}_{4}\right]_{\mathrm{ad}}+4\left[\mathrm{ZnSO}_{4}\right]_{\mathrm{ad}} \\
& +[\mathrm{NaOH}]_{\mathrm{ad}}=\left[\mathrm{Zn}(\mathrm{OH})^{+}\right]+2\left[\mathrm{Zn}(\mathrm{OH})_{2}\right] \\
& +\left[\mathrm{Zn}_{2}(\mathrm{OH})^{3+}\right]+\left[\mathrm{Ni}(\mathrm{OH})^{+}\right]+2\left[\mathrm{Ni}(\mathrm{OH})_{2}\right] \\
& +\left[\mathrm{OH}^{-}\right]+4\left[\mathrm{HSO}_{4}{ }^{-}\right]+4\left[\mathrm{SO}_{4}{ }^{2-}\right]
\end{aligned}
$$

electroneutrality [eqn. (A5)], and the equilibrium conditions [eqn. (A6)-(A10)] and

$$
\left[\mathrm{Ni}^{2+}\right]\left[\mathrm{OH}^{-}\right]^{2}-K_{5}=0
$$

The equilibrium constants and solubility products used are given in Table 1. The concentrations are determined by solving the above equations simultaneously using MAPLE.

\section{Notation}

$c_{i} \quad$ concentration of species $i, \mathrm{~mol} / \mathrm{cm}^{3}$

$E_{\mathrm{p}} \quad$ cathodic peak potential, $\mathrm{V}$

$E_{\mathrm{r}} \quad$ anodic peak potential, $\mathrm{V}$

$I_{\mathrm{av}}$ average current density, $i_{\mathrm{p}} \times t_{\mathrm{on}} /\left(t_{\mathrm{on}}+t_{\mathrm{off}}\right), \mathrm{A} \mathrm{cm}^{-2}$

$I^{\text {av }}$ dc current density, $\mathrm{A} \mathrm{cm}^{-2}$

[i] bulk concentration of species $i, \mathrm{M}$

$[i]_{\text {ad }}$ concentration of adsorbed species $i, \mathrm{M}$

$i_{\mathrm{p}} \quad$ pulse peak current, $\mathrm{A} \mathrm{cm}^{-2}$

$i_{\mathrm{r}} \quad$ pulse reverse peak current, $\mathrm{A} \mathrm{cm}^{-2}$

$K_{i} \quad$ equilibrium constant of chemical reaction $i$

$t$ time, $s$

$t_{\text {on }} \quad$ pulse time, $s$

$t_{\text {off }}$ relaxation or reversal time, $\mathrm{s}$

$v$ potential scan rate, $\mathrm{mV} \mathrm{s}^{-1}$

$z_{i} \quad$ charge number of species $i$

\section{References}

1 M. F. Mathias and T. W. Chapman, J. Electrochem. Soc., 1990, 137, 102.

2 S. H. Hessami and C. W. Tobias, J. Electrochem. Soc., 1989, 136, 3611.

3 M. F. Mathias and T. W. Chapman, J. Electrochem. Soc., 1987, 134, 1408.

4 W. C. Grande and J. B. Talbot, J. Electrochem. Soc., 1992, 140, 669.

5 B. N. Popov, Ken-Ming Yin and R. E. White, J. Electrochem. Soc., 1993, 140, 1321.

6 B. N. Popov, S. N. Popova, Ken-Ming Yin and R. E. White, Plat. Surf. Finish., 1994, 81, 65 .

7 K-M. Yin, J. H. Wei, J-R. Fu, B. N. Popov, S. N. Popova and R. E. White, J. Appl. Electrochem., 1995, 25, 543.

8 M. Ramasubramanian, S. N. Popova, B. N. Popov, R. E. White and K-M. Yin, J. Electrochem. Soc., 1996, 143, 2164.

9 Y. Imai, Sh. Ohsumi and M. Kurachi, Denki Kagaku, 1978, 46, 264.

10 Y. Imai and M. Kurachi, Denki Kagaku, 1979, 47, 89.

11 Y. Imai and M. Kurachi, Denki Kagaku, 1977, 45, 728.

12 Y. Imai, T. Watanabe and M. Kurachi, Denki Kagaku, 1978, 46, 202.

13 A. Shibuya, T. Kurimoto, Y. Hoboh and N. Usuki, Denki Kagaku, 1983, 23, 923.

14. A. Matsuda, T. Yoshihara, K. Miyachi, A. Komoda and S. Kikuchi, ISIJ, 1984, 24, B267.

15 Y-P. Lin and J. R. Selman, J. Electrochem. Soc., 1993, 140, 1299

16 Y-P. Lin and J. R. Selman, J. Electrochem. Soc., 1991, 138, 3525.

17 Y-P. Lin and J. R. Selman, Plat. Surf. Finish., 1991, 3, 26.

18 R. Albalat, E. Gomez, C. Muller, J. Pregonas, M. Sarret and E. Vales, J. Appl. Electrochem., 1991, 21, 44.

19 R. Fratesi and G. Roventi, J. Appl. Electrochem., 1992, 22, 657.

20 J. Balej, J. Divisek, H. Schmitz and J. Mergel, J. Appl. Electrochem., 1992, 22, 705 .

21 K. Nishimura, I. Kikuchi and H. Odashima, J. Surf. Technol., $1991,42,627$.

22 B. N. Popov, D. Slavkov, T. Grcev, Lj. Arsov and S. Karaivanov, Kem. Ind., 1986, $1,1$.

23 M. L. Abell and J. P. Braselton, The Maple ${ }^{\circledR}$ Handbook, Academic Press, Cambridge, MA, 1994.

24 W. Lorenz, Z. Phys. Chem. N.F., 1959, 19, 377

25 J. Matulis and R. Slizys, Electrochim. Acta, 1964, 9, 1177.

26 K. P. Staudhammer, Atlas of Binary Alloys, Marcel Dekker, New York, 1973.

27 J. Bressan and R. Wiart, J. Appl. Electrochem., 1979, 9, 43

28 P. C. Andricacos, C. Arana, J. Tabib, J. Dukovic and L. T. Romankiw, J. Electrochem. Soc., 1989, 136, 1336.

29 N. Hackerman and T. Jensen, J. Electrochem. Soc., 1952, 99, 60

30 J. C. Puippe, in Theory and Practice of Pulse Plating, ed. J. C. Puippe and F. Leaman, American Electroplaters and Surface Finishers Society, Orlando, FL, 1986, p. 17.

31 C. F. Baes and R. E. Mesemer, The Hydrolysis of Cations, John Wiley and Sons, New York, 1976.

32 CRC Handbook of Chemistry and Physics, 59th edn., ed. R. C. Weast, CRC Press, Boca Raton, FL, 1978-1979.

33 H. J. De Wijs, Recl. Trav. Chim., Pays-Bas, 1925, 44, 663. 